\title{
Genetic association between HER2 and ESR2 polymorphisms and ovarian cancer: a meta-analysis
}

This article was published in the following Dove Press journal:

OncoTargets and Therapy

\author{
Liang Tang ${ }^{1,2}$ \\ Jianming $\mathrm{Li}^{1,3}$ \\ Meihua Bao ${ }^{1,2}$ \\ Ju Xiangl,2 \\ Yiwei Chen ${ }^{1,2}$ \\ Yan Wang ${ }^{1,2,4}$
}

'Department of Human Anatomy, Histology and Embryology, Institute of Neuroscience, Changsha Medical University, Changsha, People's Republic of China; ${ }^{2}$ Department of Human Anatomy, School of Basic Medical Science, Changsha Medical University, Changsha, People's Republic of China; ${ }^{3}$ Department of Neurology, Xiang-ya Hospital, Central South University, Changsha, People's Republic of China; ${ }^{4}$ Department of Human Anatomy, Experiment Center for Function, Changsha Medical University, Changsha, People's Republic of China
Correspondence: Yan Wang; Yiwei Chen Department of Human Anatomy, Histology and Embryology, Institute of Neuroscience, Changsha Medical University, Changsha 410219, People's Republic of China Tel/fax +86 73I 88602635 Email yanwang87I214@I63.com; yiwei_chen89@I63.com
Objective: The estrogen receptor (ER) and the human epidermal growth factor receptor 2 (HER2) each play an important role in female cancers. This study aimed to investigate the genetic association between three common single nucleotide polymorphisms (SNPs) and the risk of ovarian cancer. The SNPs investigated in this study were ESR2 rs1271572 and rs3020450 and HER2 rs1801200.

Methods: In this study, databases were electronically searched in a meta-analysis. Databases used were PubMed, Embase, China National Knowledge Infrastructure (CNKI), Wanfang and Cochrane library. Case-control studies on the association between ESR2 and HER2 polymorphisms were selected according to inclusion and exclusion standard. Articles were evaluated for quality, and data were extracted.

Results: A total of 13 articles with 5,461 cases and 7,603 controls were included in this metaanalysis. The recessive model of ESR2 rs 1271572 was shown to be significantly associated with the risk of ovarian cancer $(p=0.008$, odds ratio [OR] [95\% confidence interval $\{\mathrm{CI}\}]=1.13[1.03$, 1.24]), and this significant association still existed in a subgroup analysis stratified by ethnicity (Asian: $p=0.04$, OR $[95 \% \mathrm{CI}]=1.92[1.04,3.56]$; Caucasian: $p=0.02, \mathrm{OR}[95 \% \mathrm{CI}]=1.12$ $[1.02,1.23])$. In addition, the distribution of the dominant model of ESR2 rs3020450 was significantly different in the total group $(p=0.02$, OR $[95 \% \mathrm{CI}]=0.71[0.53,0.95])$ and the Caucasian subgroup $(p=0.02$, OR $[95 \% \mathrm{CI}]=0.67[0.48,0.94])$. Furthermore, no significant association between allelic, dominant, codominant and recessive models of HER2 rs1801200 (V655I) and ovarian cancer was found ( $p>0.05)$.

Conclusion: The recessive model of ESR2 rs1271572 and the dominant model of ESR2 rs3020450 might be susceptible factors for ovarian cancer.

Keywords: ESR2, ovarian cancer, HER2, meta-analysis

\section{Introduction}

Ovarian cancer is one of the most lethal female cancers in women with $15 \%-25 \%$ 5-year overall survival rates. ${ }^{1}$ Family and twin studies suggested that genetic factors are one of the important causes of ovarian cancer. ${ }^{2}$ The most well-documented inherited factors are the BRCA1 and BRCA12 genes. ${ }^{3,4}$ However, these two genes account for $<40 \%$ of the established ovarian cancer risk, indicating that there are other yet unexplained genetic factors contributing to ovarian cancer. It is widely accepted that tumor formation is a multistep process accompanied by an accumulation of multiple genetic alterations. Recently, a number of genes referring to DNA repair (BRCA1interacting protein 1 [BRIP1 $]^{5}$ and $\mathrm{FANCJ}^{6}$ ), etinoblastoma-1 (RB1), ${ }^{7}$ estrogen receptor (ER) genes (ESR1 and ESR2 ${ }^{8,9}$ ) and vitamin D receptor (VDR) genes ${ }^{10}$ have been reported to be associated with the susceptibility of ovarian cancer.

Research has shown that increasing levels of estrogen may increase the risk of ovarian cancer by binding to the ER- $\alpha$, encoded by ESR 1 . The target of action enhances 
cell proliferation, apoptosis and migration. ${ }^{11,12}$ However, the specific functions of the ER- $\beta$, encoded by ESR2 in cancer, are not yet clear. There is evidence that ESR2 mRNA was highly expressed in normal ovarian tissue when compared to tumor tissue, ${ }^{13,14}$ which indicated a tumor suppressive role of ER- $\beta$ in ovary. Human epidermal growth factor receptor 2 (HER2), a member of the HER receptor tyrosine kinase family, is a well-known susceptible factor in breast cancer. ${ }^{15,16}$ HER2 was reported to interact with the ER and regulate tumor cell proliferation and survival. ${ }^{17}$ Overexpression of HER 2 was observed in up to $20 \%-30 \%$ of breast and ovarian cancers. ${ }^{18}$ These data suggest an important role of ESR2 and HER2 in the susceptibility of ovarian cancer.

In recent years, a multitude of single nucleotide polymorphisms (SNPs) both in HER2 and ESR2 genes have been reported to be associated with the risk of ovarian cancer. In the human HER2 gene, a common SNP called rs1801200 (V655I) was identified in the transmembrane coding region at codon 655 that encodes either isoleucine (ATC) or valine (GTC). ${ }^{19}$ Four studies investigated the genetic association between this SNP and the risk of ovarian cancer. ${ }^{20-23}$ In addition, only two studies reported that Val/Val homozygosity was significantly associated with ovarian cancer. ${ }^{21,23}$ For ESR2, rs1271572 was suggested to be an ovarian cancer susceptibility marker in Japanese, ${ }^{24}$ Australian, ${ }^{9}$ and Caucasian (Hawaii) patients. ${ }^{24}$ However, these results cannot be replicated in German, American, Polish, Danish and British patients. ${ }^{9,26,27}$

Owing to the inconsistent and inconclusive results found in the literature, it is the aim of this study to get a more precise and comprehensive understanding of the association between polymorphisms in the ESR2 and HER2 genes and ovarian cancer using a meta-analysis.

\section{Methods}

\section{Literature search strategy}

This study was conducted and reported according to the Preferred Reporting Items for Systematic Reviews and MetaAnalyses (PRISMA) guidelines. ${ }^{28}$ Two authors searched the databases PubMed, Embase, China National Knowledge Infrastructure (CNKI), Wanfang and Cochrane Library using the following terms: "Estrogen receptor 2", "ESR2", "Human epidermal growth factor receptor 2", "HER2", "polymorphism", "single nucleotide polymorphism", "SNP", "ovarian cancer" and "ovarian carcinoma" up to July 1, 2017. There was no limitation in language. All the results from the databases were screened. All available results from the database were screened starting with the title. Then, the abstracts were screened in the articles where the title fulfilled the criteria. Other potentially relevant articles were identified by cross-references within eligible studies.

\section{Inclusion/exclusion criteria}

The inclusion criteria were as follows: 1) case-control design; 2) regarding ESR2 or HER2 polymorphisms and ovarian cancer risk and 3 ) included allelic or genotype frequencies in cases and controls.

The exclusion criteria were as follows: 1) not regarding ESR2 or HER2 polymorphisms and ovarian cancer risk; 2) duplicate publications; 3 ) case reports, letters, commentaries, meeting records or review articles and 4) insufficient published data for calculating an odds ratio (OR) with $95 \%$ confidence interval (CI).

\section{Data extraction}

The following information from each study was summarized: first author, year of publication, ethnicity, number of cases and controls, mean age of cases and controls, gender component in cases and controls, genotyping method, sample source, SNPs and evidence of Hardy-Weinberg equilibrium (HWE) in the control group by L. T. and Y. W. Any disagreements were resolved by the third author (J. X.).

\section{Quality assessment}

The quality of the research found in the articles was accessed independently according to the Newcastle-Ottawa Scale (NOS) by J. L. and M. B. ${ }^{28}$ A quality score was calculated from group selection and comparability and assessment of outcome or exposure. Any discrepancies in the assessment were resolved by the third author (L. T.).

\section{Statistical analysis}

Crude OR and 95\% CI were calculated to test the strength of associations between the allelic, dominant, codominant and recessive models of ESR2 or HER2 polymorphisms and ovarian cancer susceptibility. The significance of the pooled OR was determined by the $Z$-test. Heterogeneity was conducted using Cochran's Q test and $I^{2}$ statistics. $I^{2}$ values of $>50 \%$ indicated heterogeneity among studies. A random effects model was applied if heterogeneity was observed $\left(I^{2}>50 \%\right)$. Otherwise, the fixed effects model was used. Sensitivity analysis was performed to assess the effects of individual studies on pooled results and the stability of the results. Publication bias was accessed using funnel plots by the methods of Begg's test 
and Egger's test. A value of $p<0.05$ was considered to be statistically significant. The statistical tests were performed using the Stata software (version 12.0; StataCorp LP, College Station, TX, USA) and RevMan software (version 5.1; The Nordic Cochrane Centre, Copenhagen, Denmark).

\section{Results Study characteristics}

A total of 333 articles for HER2 and 1,152 articles for ESR2 were identified through the literature search. After reviewing the titles, abstracts and full-texts, finally four eligible articles for HER $2^{20-23}$ and three studies with nine populations for ESR2 $2^{9,24,26,27}$ were included in the present study. Each population was treated as an individual study. Thus, nine studies were collected for ESR2 in this meta-analysis. The detailed steps of our literature search are shown in Figure 1. The information for the selected studies is summarized in Table 1. Four studies with 348 cases and 540 controls confirmed the association between HER2 rs1801200 (V655I) and ovarian cancer. Nine studies with 5,109 cases and 6,893 controls confirmed the association between ESR rs1271572 and rs3020450 and ovarian cancer.

\section{Meta-analysis results}

Significant association was detected between ESR2 rs1271572 and ovarian cancer in the recessive model. The genetic association between the recessive model rs1271572 and ovarian cancer was found in both Asian and Caucasian subgroups (Asian: $p=0.04$, OR [95\% CI] $=1.92[1.04,3.56]$; Caucasian: $p=0.02$, OR $[95 \% \mathrm{CI}]=1.12[1.02,1.23])$ but not in the total group $(p>0.05)$. No significant association was detected between allelic, codominant and dominant models of ESR2 rs1271572 and ovarian cancer $(p>0.05$; Table 2 and Figure 2).

For rs3020450, a significant difference was observed between the frequency of the dominant model ( $p=0.02$, OR $[95 \% \mathrm{CI}]=0.71[0.53,0.95])$ and ovarian cancer. However, the significant difference was only found in Caucasian but not in Asian (Asian: $p=0.52$, OR $[95 \% \mathrm{CI}]=0.84$ $[0.49,1.44]$; Caucasian: $p=0.02$, OR $[95 \% \mathrm{CI}]=0.67[0.48$, 0.94]). No significant association was detected between rs3020450 and ovarian cancer in allelic, codominant and recessive models ( $p>0.05$; Table 2 and Figure 3). Furthermore, no association was detected between allelic, codominant, recessive and dominant models of HER2 rs1801200 (V655I) and the risk of ovarian cancer $(p>0.05$; Table 2 and Figure 4).
333 records of HER2 identified through database searching 1,152 records of ESR2 identified through database searching

326 records of HER2 after duplicates removed 1,141 records of ESR2 after duplicates removed

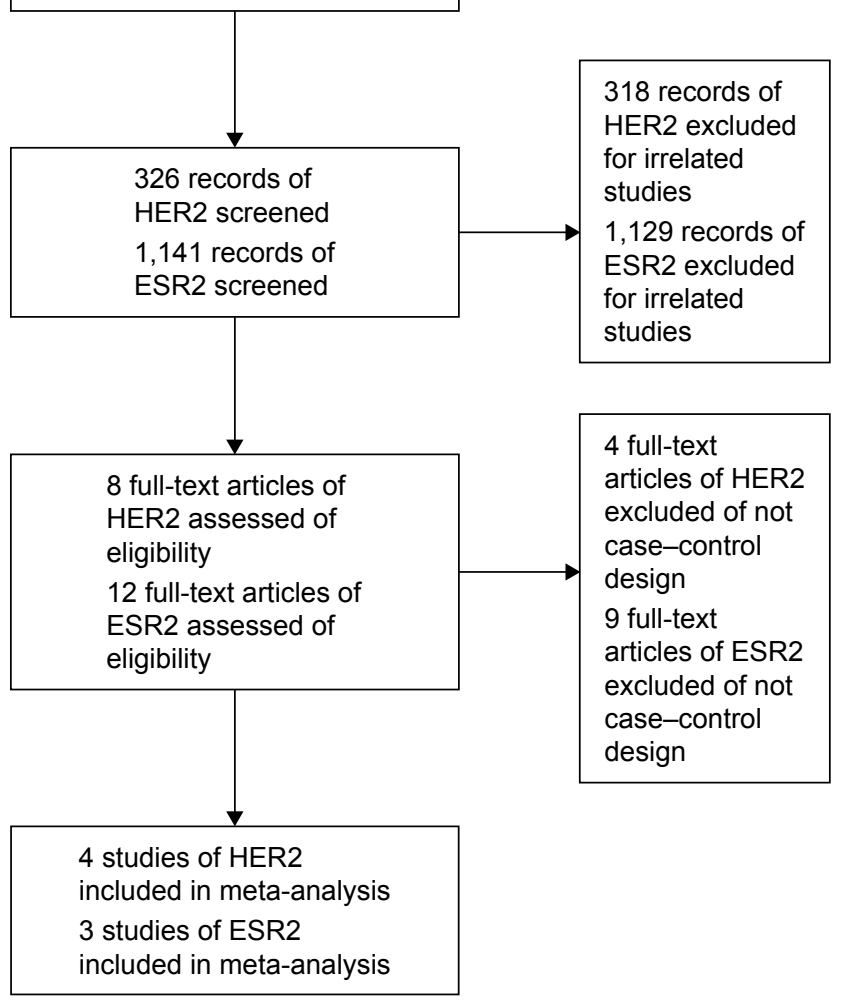

Figure I PRISMA flow chart regarding inclusion and exclusion criteria of studies. Abbreviation: PRISMA, Preferred Reporting Items for Systematic Reviews and Meta-Analyses.

\section{Sources of heterogeneity}

Significant heterogeneities were detected in the allelic model of rs1271572 in the total group and the Caucasian subgroup (total group: $I^{2}=89 \%$; Caucasian subgroup: $I^{2}=89 \%$ ). The heterogeneity in this SNP was contributed primarily by an American population. ${ }^{9}$ Removal of this study from the meta-analysis gave $0 \%(p=0.63)$ heterogeneity and showed that it had the highest effect on the association between the allelic model of rs1271572 and ovarian cancer. In addition, significant heterogeneities were also found in the allelic, dominant, codominant and recessive models of HER rs1801200 (V655I) in the total group (allelic: $I^{2}=93 \%$, dominant: $I^{2}=69 \%$, codominant: $I^{2}=66$, 


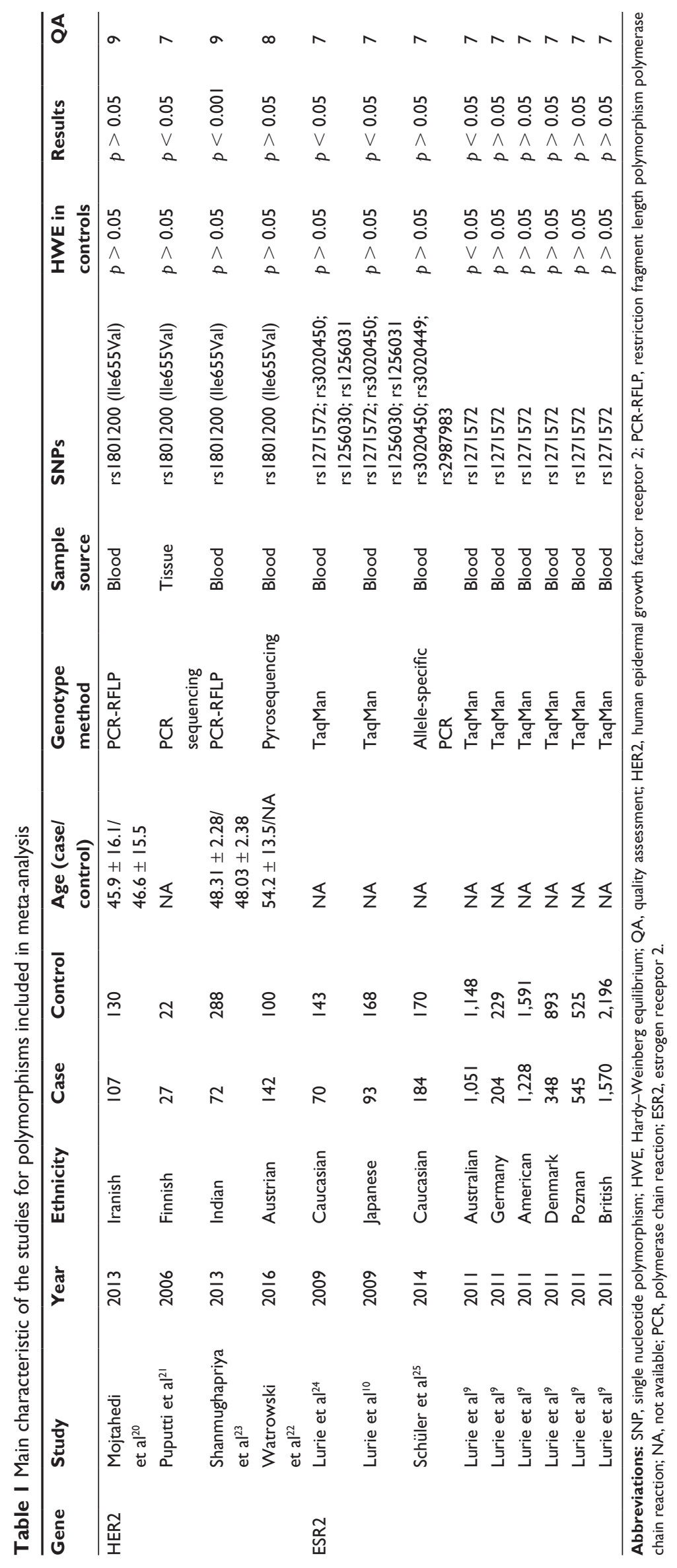


Table 2 The results of meta-analysis for ESR2 rs I27I572, rs3020450 and HER2 rs I80I200 (Val655lle) and risk of ovarian cancer

\begin{tabular}{|c|c|c|c|c|c|c|c|c|c|c|}
\hline \multirow[t]{2}{*}{ Gene } & \multirow[t]{2}{*}{$\begin{array}{l}\text { SNPs } \\
\text { (minor allele) }\end{array}$} & \multirow[t]{2}{*}{ Genetic model } & \multirow[t]{2}{*}{$\begin{array}{l}\text { Number } \\
\text { of studies }\end{array}$} & \multicolumn{2}{|c|}{ Numbers } & \multicolumn{2}{|l|}{ Test of association } & \multirow[t]{2}{*}{ Model } & \multicolumn{2}{|c|}{$\begin{array}{l}\text { Test of } \\
\text { heterogeneity }\end{array}$} \\
\hline & & & & Case & Control & OR (95\% Cl) & p-value & & $p$-value & $I^{2}(\%)$ \\
\hline \multirow[t]{32}{*}{ ESR2 } & rs I $27 \mid 572(\mathrm{~T})$ & Allelic (T) & & & & & & & & \\
\hline & & Total & 8 & 10,218 & 13,786 & $1.02(0.86,1.21)$ & 0.79 & $\mathrm{R}$ & $<0.00001$ & 89 \\
\hline & & Asian & I & 186 & 336 & I.4I $(0.98,2.03)$ & 0.06 & - & - & - \\
\hline & & Caucasian & 7 & 10,032 & 13,450 & $0.99(0.83,1.18)$ & 0.91 & $\mathrm{R}$ & $<0.00001$ & 89 \\
\hline & & Dominant (TT + GT/GG) & & & & & & & & \\
\hline & & Total & 8 & 5,109 & 6,893 & $1.01(0.93,1.09)$ & 0.79 & $\mathrm{~F}$ & 0.93 & 0 \\
\hline & & Asian & I & 93 & 168 & $1.32(0.77,2.28)$ & 0.31 & - & - & - \\
\hline & & Caucasian & 7 & 5,016 & 6,725 & $1.00(0.93,1.09)$ & 0.91 & $\mathrm{~F}$ & 0.96 & 0 \\
\hline & & Recessive (TT/GT + TT) & & & & & & & & \\
\hline & & Total & 8 & 5,109 & 6,893 & $1.13(1.03,1.24)$ & 0.008 & $\mathrm{~F}$ & 0.24 & 24 \\
\hline & & Asian & I & 93 & 168 & $1.92(1.04,3.56)$ & 0.04 & - & - & - \\
\hline & & Caucasian & 7 & 5,016 & 6,725 & $1.12(1.02,1.23)$ & 0.02 & $\mathrm{~F}$ & 0.39 & 4 \\
\hline & & Codominant (TT/GG) & & & & & & & & \\
\hline & & Total & 8 & 2,610 & 3,380 & $1.10(0.99,1.23)$ & 0.06 & $\mathrm{~F}$ & 0.83 & 0 \\
\hline & & Asian & I & 63 & 88 & $1.49(0.75,2.93)$ & 0.25 & - & - & - \\
\hline & & Caucasian & 7 & 2,547 & 3,292 & $1.10(0.99,1.22)$ & 0.09 & $\mathrm{~F}$ & 0.84 & 0 \\
\hline & rs3020450 (A) & Allelic (A) & & & & & & & & \\
\hline & & Total & 3 & 694 & 962 & $0.87(0.70,1.09)$ & 0.23 & $\mathrm{~F}$ & 0.29 & 19 \\
\hline & & Asian & I & 186 & 336 & $1.06(0.67,1.66)$ & 0.81 & - & - & - \\
\hline & & Caucasian & 2 & 508 & 626 & $0.83(0.64,1.06)$ & 0.14 & $\mathrm{~F}$ & 0.21 & 37 \\
\hline & & Dominant (AA + AG/GG) & & & & & & & & \\
\hline & & Total & 3 & 347 & 481 & $0.7 \mathrm{I}(0.53,0.95)$ & 0.02 & $\mathrm{~F}$ & 0.34 & 8 \\
\hline & & Asian & I & 93 & 168 & $0.84(0.49,1.44)$ & 0.52 & - & - & - \\
\hline & & Caucasian & 2 & 254 & 313 & $0.67(0.48,0.94)$ & 0.02 & $\mathrm{~F}$ & 0.19 & 41 \\
\hline & & Recessive (AA/AG + GG) & & & & & & & & \\
\hline & & Total & 3 & 347 & 481 & $1.32(0.84,2.08)$ & 0.23 & $\mathrm{~F}$ & 0.23 & 32 \\
\hline & & Asian & I & 93 & 168 & $3.07(0.97,9.67)$ & 0.06 & - & - & - \\
\hline & & Caucasian & 2 & 254 & 313 & $1.12(0.68,1.85)$ & 0.65 & $\mathrm{~F}$ & 0.48 & 0 \\
\hline & & Codominant (AA/GG) & & & & & & & & \\
\hline & & Total & 3 & 235 & 298 & $1.21(0.75,1.95)$ & 0.43 & $\mathrm{~F}$ & 0.25 & 29 \\
\hline & & Asian & I & 73 & 118 & $2.78(0.87,8.86)$ & 0.08 & - & - & - \\
\hline & & Caucasian & 2 & 162 & 180 & $1.02(0.60,1.72)$ & 0.94 & $\mathrm{~F}$ & 0.52 & 0 \\
\hline \multirow[t]{16}{*}{ HER2 } & rs 1801200 & Allelic (V) & & & & & & & & \\
\hline & (V655I) (V) & Total & 4 & 696 & $\mathrm{I}, 080$ & $1.03(0.37,2.83)$ & 0.96 & $\mathrm{R}$ & $<0.00001$ & 93 \\
\hline & & Asian & 2 & 358 & 836 & $1.70(0.49,5.87)$ & 0.40 & $\mathrm{R}$ & 0.0005 & 92 \\
\hline & & Caucasian & 2 & 338 & 244 & $0.58(0.22,1.50)$ & 0.26 & $\mathrm{R}$ & 0.05 & 73 \\
\hline & & Dominant (VV + VI/II) & & & & & & & & \\
\hline & & Total & 4 & 348 & 540 & I.I5 $(0.64,2.07)$ & 0.64 & $\mathrm{R}$ & 0.02 & 69 \\
\hline & & Asian & 2 & 179 & 418 & $1.55(0.59,4.09)$ & 0.38 & $\mathrm{R}$ & 0.02 & 82 \\
\hline & & Caucasian & 2 & 169 & 122 & $0.83(0.5 \mathrm{I}, \mathrm{I} .34)$ & 0.45 & $\mathrm{~F}$ & 0.68 & 0 \\
\hline & & Recessive (VV/VI + II) & & & & & & & & \\
\hline & & Total & 4 & 348 & 540 & $3.67(0.83,16.36)$ & 0.09 & $\mathrm{R}$ & 0.04 & 63 \\
\hline & & Asian & 2 & 179 & 418 & $2.79(0.07,105.02)$ & 0.58 & $\mathrm{R}$ & 0.006 & 87 \\
\hline & & Caucasian & 2 & 169 & 122 & $3.36(1.02,11.03)$ & 0.05 & $\mathrm{~F}$ & 0.65 & 0 \\
\hline & & Codominant (VV/II) & & & & & & & & \\
\hline & & Total & 4 & 263 & 417 & $3.44(0.72,16.50)$ & 0.12 & $\mathrm{R}$ & 0.03 & 66 \\
\hline & & Asian & 2 & 139 & 341 & $2.9 \mid(0.07,122.22)$ & 0.58 & $\mathrm{R}$ & 0.005 & 88 \\
\hline & & Caucasian & 2 & 124 & 76 & $2.93(0.88,9.72)$ & 0.08 & $\mathrm{~F}$ & 0.74 & 0 \\
\hline
\end{tabular}

Abbreviations: ESR2, estrogen receptor 2; HER2, human epidermal growth factor receptor 2; SNP, single nucleotide polymorphism; OR, odds ratio; Cl, confidence interval; $\mathrm{R}$, random model; F, fixed model; $\mathrm{V}$, val; I, ile.

recessive: $I^{2}=63 \%$ ), Asian subgroup (allelic: $I^{2}=92 \%$, dominant: $I^{2}=82 \%$, codominant: $I^{2}=88$, recessive: $I^{2}=87 \%$ ) and Caucasian subgroup (allelic: $I^{2}=73 \%$ ), with the exception of the dominant, codominant and recessive models in the
Caucasian subgroup. The heterogeneity in this variant was contributed primarily by two studies. ${ }^{22,23}$ Removal of these two studies from the meta-analysis gave $0 \%(p=0.80)$ heterogeneity and showed that they had the highest effect 


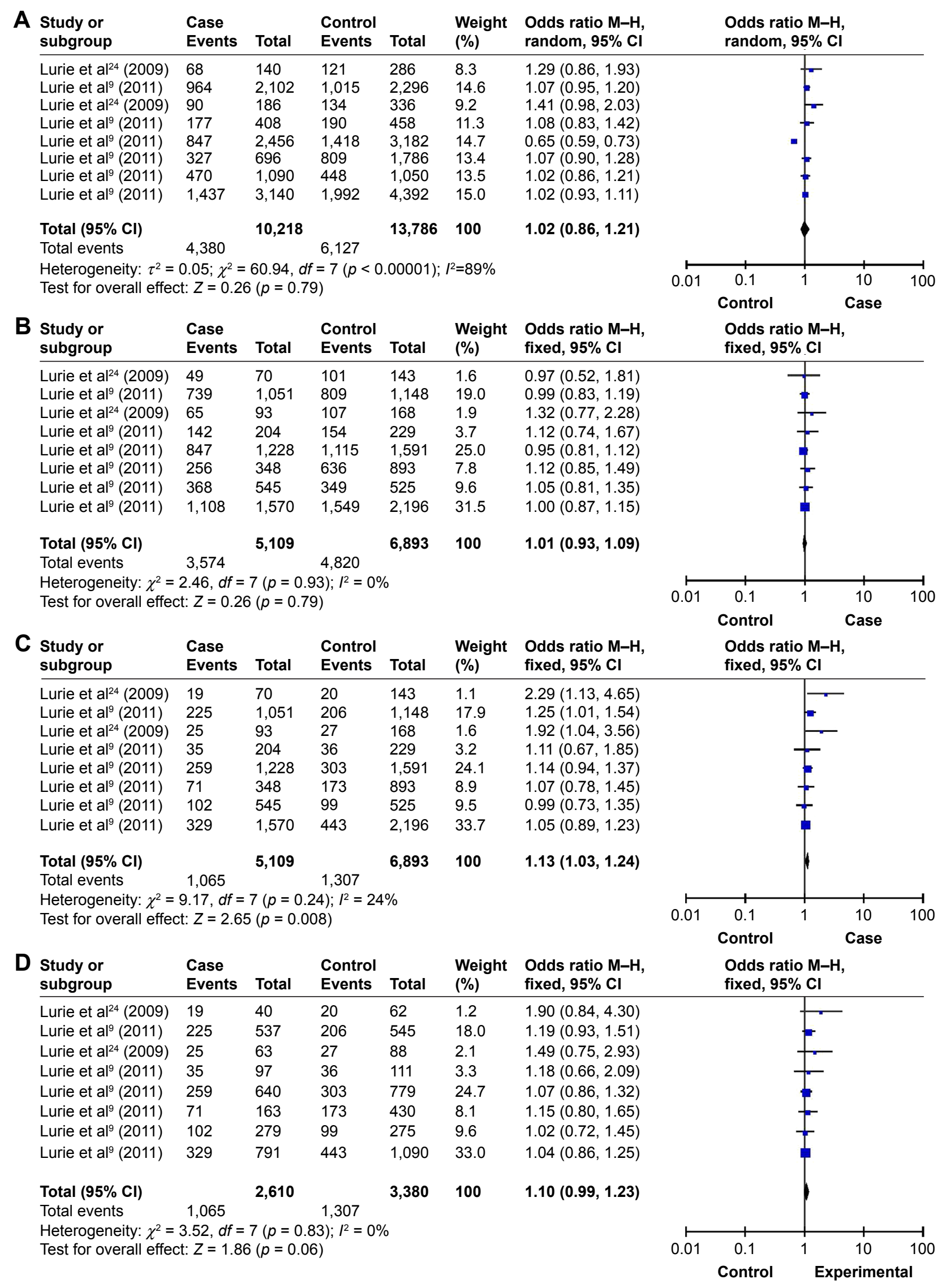

Figure 2 Forest plots of ORs for the association between ESR2 rs 1271572 and ovarian cancer. Note: (A) Allelic model, (B) dominant model, (C) recessive model and (D) codominant model. Abbreviations: OR, odds ratio; $\mathrm{M}-\mathrm{H}$, Mantel-Haenszel; $\mathrm{Cl}$, confidence interval. 


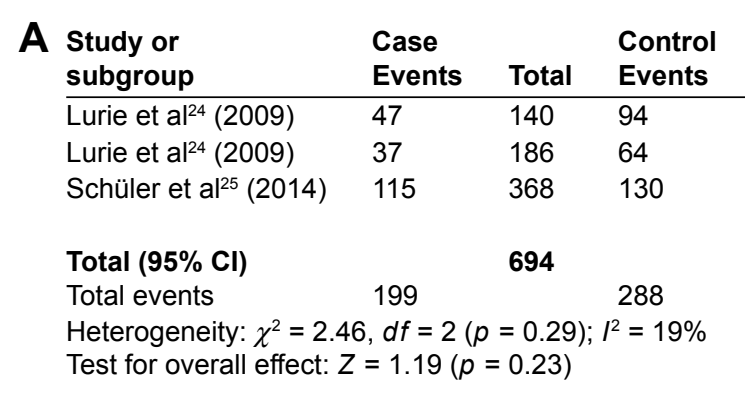

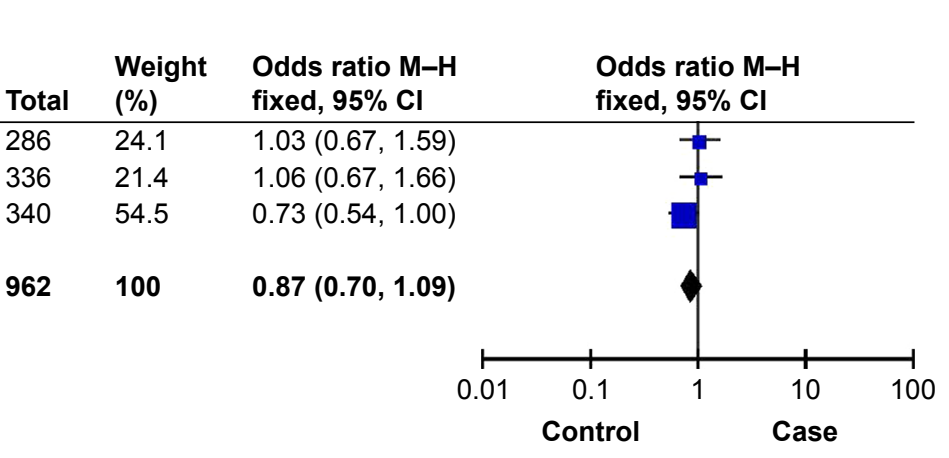

\begin{tabular}{|c|c|c|c|}
\hline $\begin{array}{l}\text { B Study or } \\
\text { subgroup }\end{array}$ & $\begin{array}{l}\text { Case } \\
\text { Events }\end{array}$ & Total & $\begin{array}{l}\text { Contro } \\
\text { Events }\end{array}$ \\
\hline Lurie et $\mathrm{al}^{24}(2009)$ & 38 & 70 & 81 \\
\hline Lurie et $\mathrm{a}^{24}(2009)$ & 29 & 93 & 59 \\
\hline Schüler et al ${ }^{25}$ (2014) & 89 & 184 & 106 \\
\hline Total $(95 \% \mathrm{Cl})$ & \multicolumn{3}{|c|}{347} \\
\hline Total events & 156 & & 246 \\
\hline $\begin{array}{l}\text { Heterogeneity: } \chi^{2}=2 \text {. } \\
\text { Test for overall effect: }\end{array}$ & $\begin{array}{l}7, d f=2 \\
=2.30\end{array}$ & $\begin{array}{r}=0.34 \\
=0.02)\end{array}$ & $I^{2}=8^{\circ}$ \\
\hline
\end{tabular}

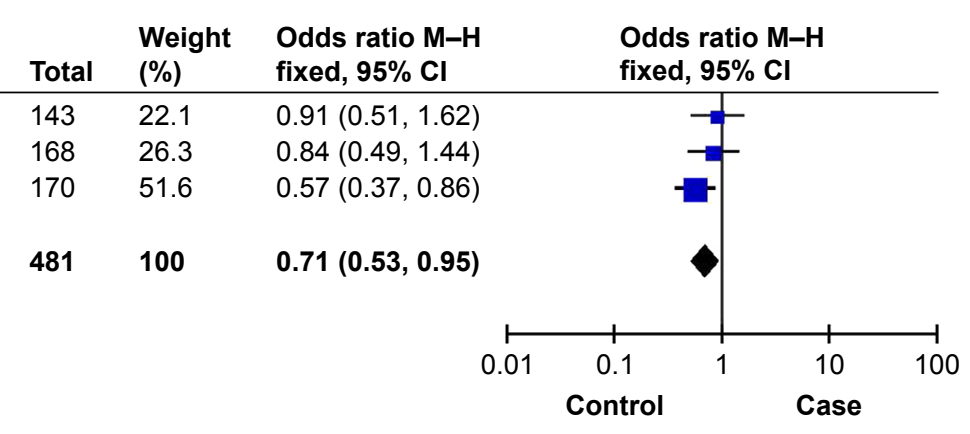

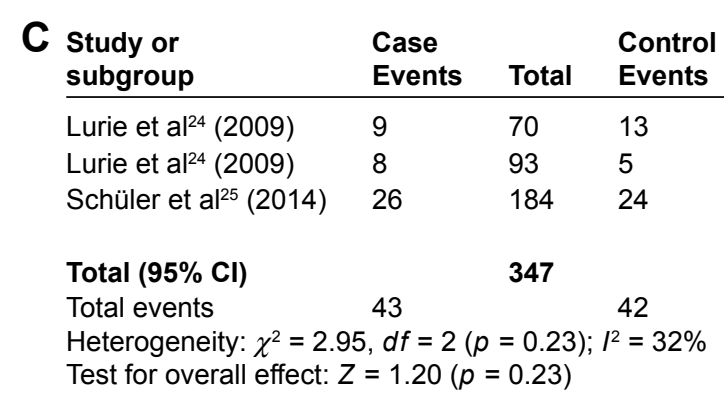

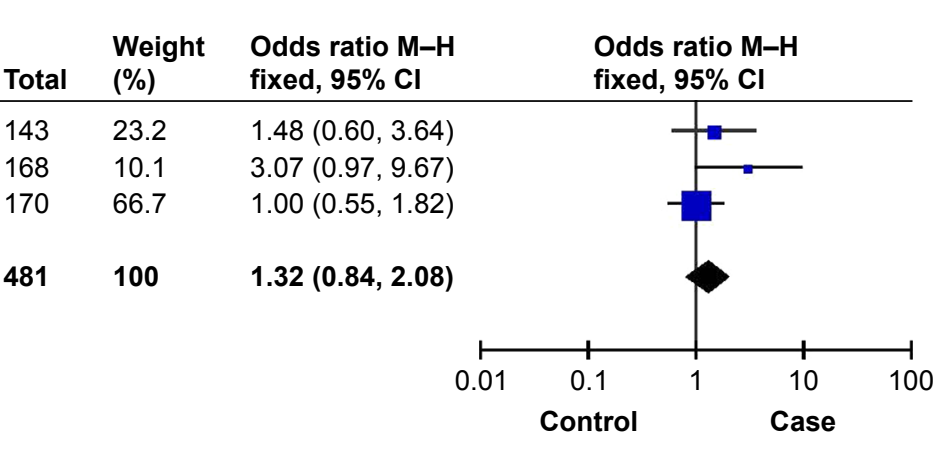

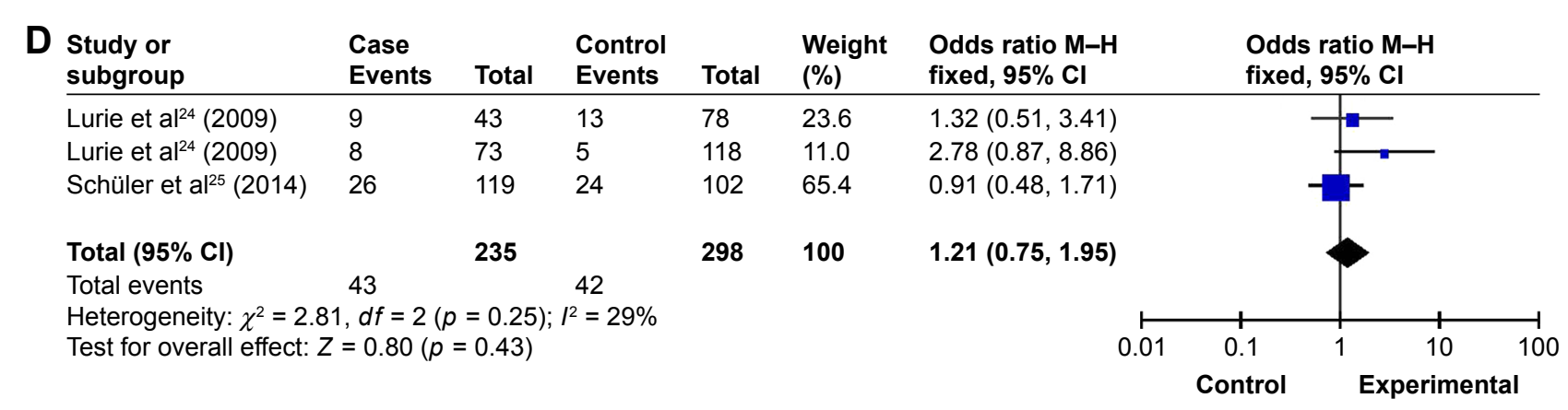

Figure 3 Forest plots of ORs for the association between ESR2 rs3020450 and ovarian cancer. Note: (A) Allelic model, (B) dominant model, (C) recessive model and (D) codominant model. Abbreviations: OR, odds ratio; $\mathrm{M}-\mathrm{H}$, Mantel-Haenszel; $\mathrm{Cl}$, confidence interval.

on the association between allelic, dominant, codominant and recessive models of HER rs1801200 (V655I) and ovarian cancer.

\section{Sensitivity analysis}

Sensitivity analysis that excluded the influence of a single study on the overall risk estimate by excluding one study at a time was confirmed. The ORs were not significantly altered in each SNP (Figure 5).

\section{Publication bias}

Begg's and Egger's tests were carried out to evaluate the publication bias. The shape of the funnel plot did not reveal any obvious asymmetry (Figure 6). The $p$-values for the Egger's test and Begg's test are shown in Table 3 separately.

\section{Discussion}

The meta-analysis presented here demonstrates that the recessive model ESR2 rs1271572 and the dominant model 


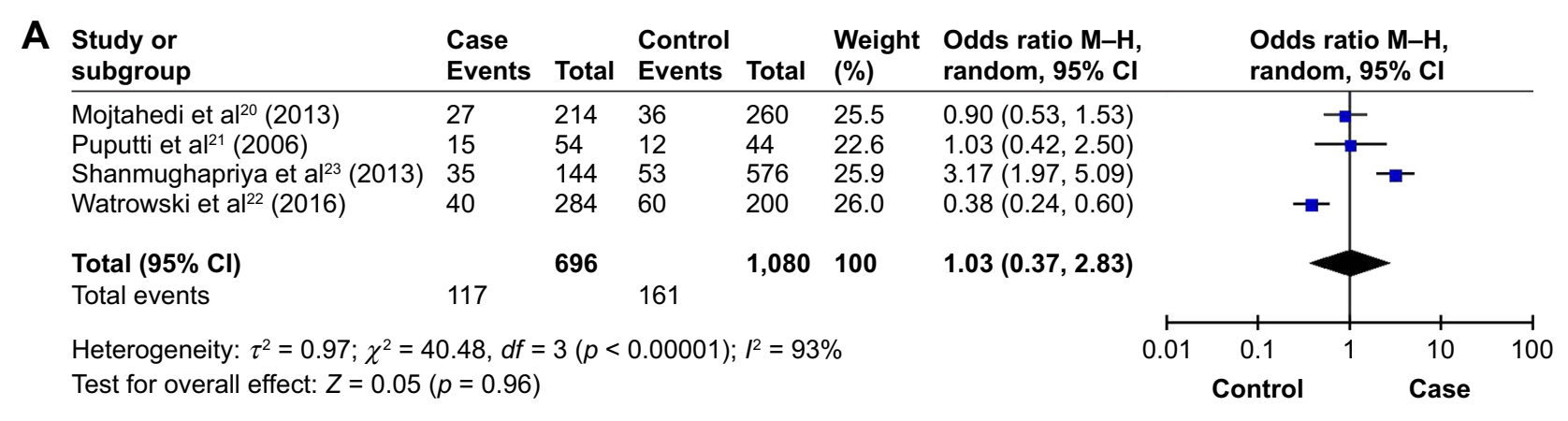

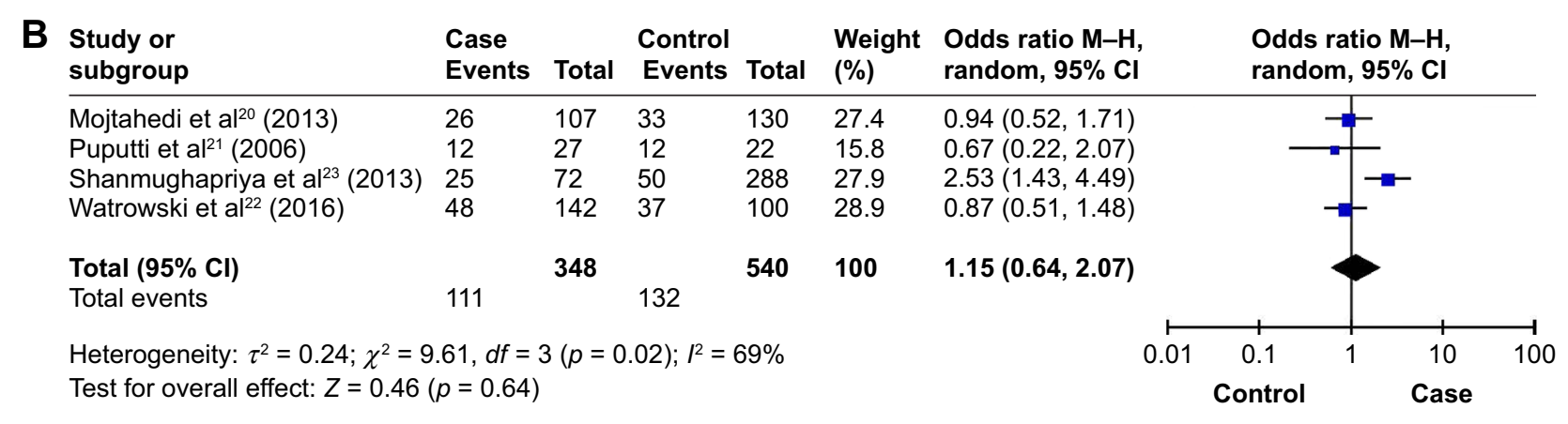

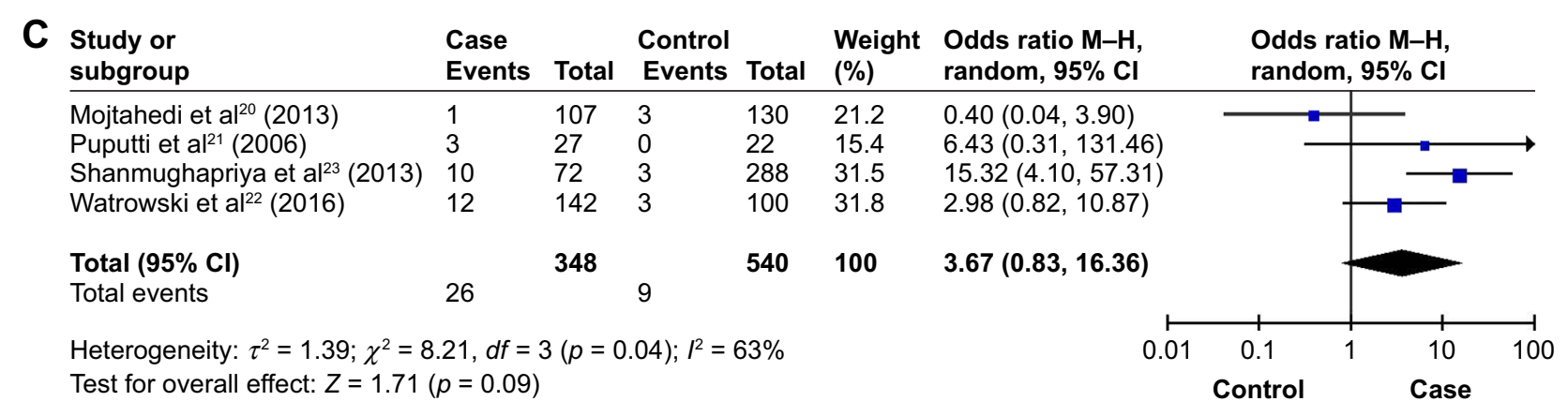

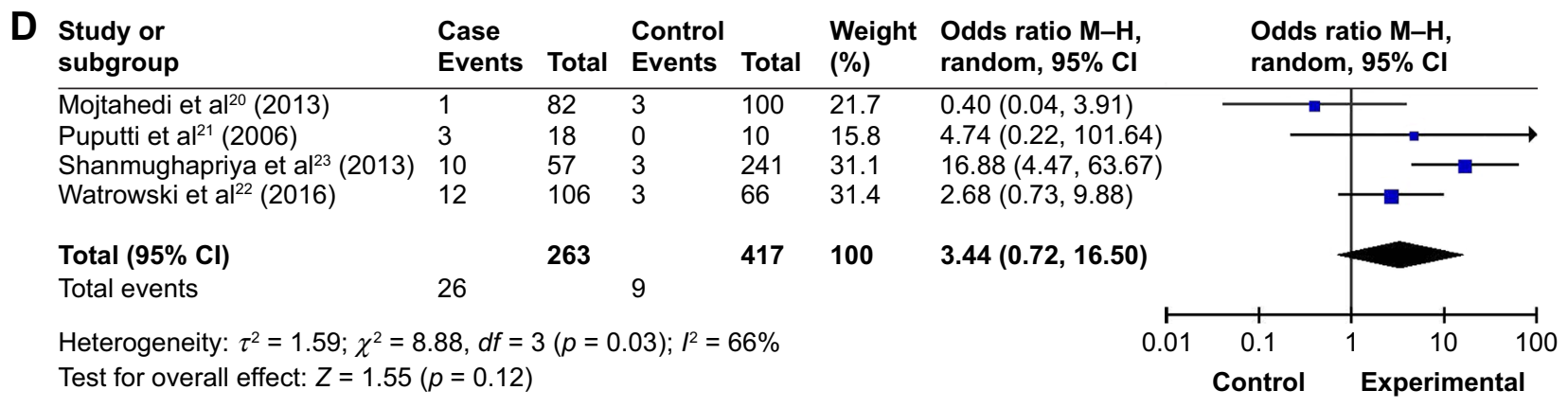

Figure 4 Forest plots of ORs for the association between HER2 rs I80I200 (V655I) and ovarian cancer.

Note: (A) Allelic model, (B) dominant model, (C) recessive model and (D) codominant model.

Abbreviations: OR, odds ratio; $\mathrm{M}-\mathrm{H}$, Mantel-Haenszel; $\mathrm{Cl}$, confidence interval.

ESR2 rs3020450 are significantly associated with the risk of ovarian cancer.

A significant association was detected between the recessive model ESR2 rs1271572 and ovarian cancer. This SNP was previously associated with the risk of breast, prostate and ovarian cancers. ${ }^{27,29,30}$ The rs1271572 gene is located in the ESR2 promoter region (-53 bp upstream), close to the AP-4/MyoD binding site. This has been identified as a region of predicted intense transcription factor binding that might influence gene expression. ${ }^{31}$ The variation in rs1271572 might interfere with some of the ER- $\beta$-proposed antiproliferative effects by altering ESR2 responsiveness to transcription 
A

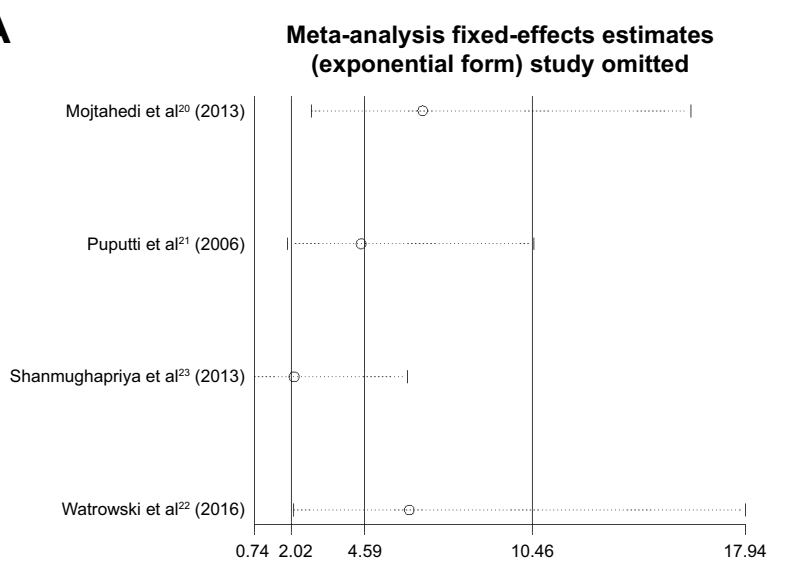

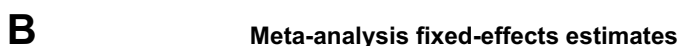

B Meta-analysis fixed-effects estimates (exponential form) study omitted

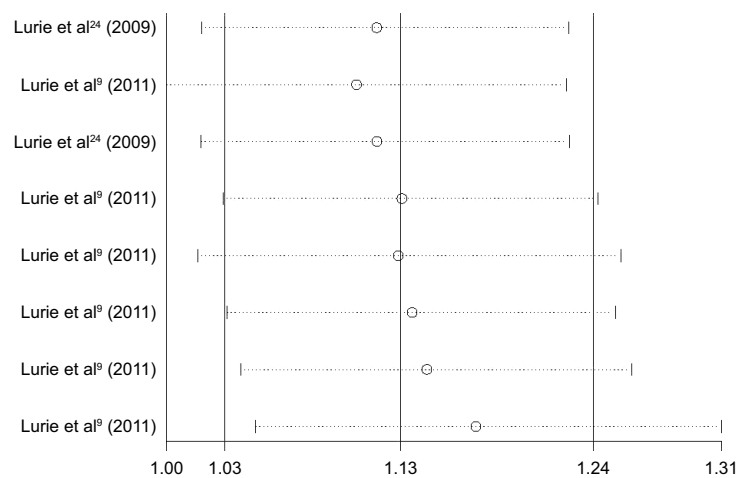

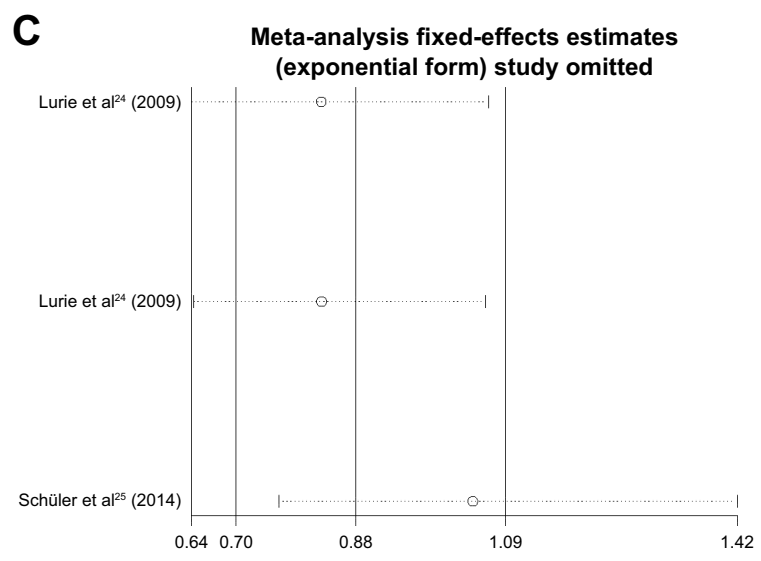

Figure 5 Sensitivity analyses between allelic models of ESR2 rs 127I572, rs3020450 and HER2 rs I80 I 200 (V655I).

Note: (A) HER2 rsI80I200 (V655I), (B) ESR2 rs I 27 I572 and (C) ESR2 rs3020450.

regulators. ${ }^{14}$ Previously, Leigh et al evaluated ${ }^{26}$ ESR2 variations in relation to ovarian cancer risk using a haplotype approach. No statistically significant associations were found. Additionally, another large study of the Ovarian Cancer Association Consortium examined ESR2 rs1271572 and found it to be weakly associated with susceptibility to ovarian cancer. ${ }^{9}$ Notably, a significant association was detected between rs1271572 and epithelial ovarian cancer in Americans. ${ }^{24}$ The inconsistent results for this SNP in different populations may be due to the limited number of subjects included in case-control studies and complex genetic background in these populations. In the present meta-analysis, we observed a significant correlation of rs1271572TT, but not rs 1271572T, and ovarian cancer in Asian and Caucasian subgroups, which indicated that the homozygote of rs 1271572 may be the risk factor of ovarian cancer susceptibility.

Our combined analysis on the association between ESR2 rs3020450 and ovarian cancer was not in line with recent individual studies analyzing this polymorphism. None of the three studies ${ }^{24-26}$ showed positive results on the correlation of rs3020450 and ovarian cancer risk, which may be due to the relatively small sample size in the combined studies. However, our meta-analysis indicated that the dominant model rs3020450 might be associated with the risk of ovarian cancer in Caucasians, but not in Asians. The different ethnic background in each group may lead to this inconsistency. The results of the present meta-analysis should be interpreted carefully due to the relatively small sample size in the Caucasian and Asian groups. To confirm these results, studies with larger sample sizes are necessary.

Given that in the ESR2 gene no non-synonymous exon SNPs exist (which would lead to an altered amino acid sequence of the ER- $\beta$ protein), the function of SNPs in the promoter region of the ESR2 genes such as rs3020450, rs2987983 and rs3020449 has been taken into account. The hypothesis was that SNPs located in this region could be able to affect binding of enhancer or repressor proteins regulating the transcription of the ESR2 gene. Altered ER- $\beta$ protein levels could then modulate estrogen effects on cancer development. ${ }^{32}$

The recessive model HER2 rs1801200 (V655I) was not associated with the risk of ovarian cancer. We initially 

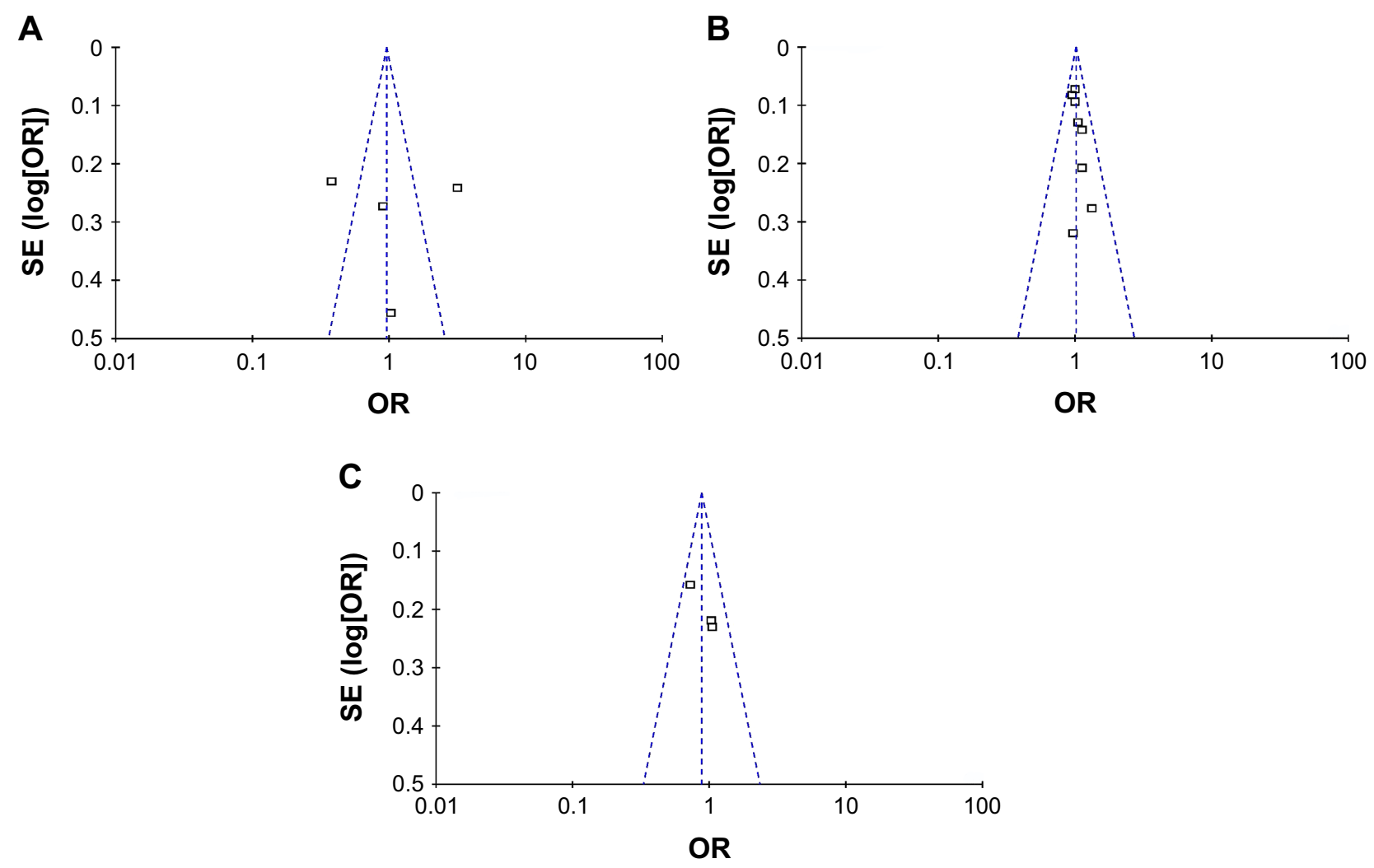

Figure 6 Funnel plots of ESR2 rs 127 I 572 and rs3020450 and HER2 rs I 80 I 200 (V655I). Note: (A) HER2 rs I80I 200 (V655I), (B) ESR2 rs I27I572 and (C) ESR2 rs3020450. Abbreviations: SE, standard error; OR, odds ratio.

detected the relationship of HER2 rs1801200 (V655I) with the risk of ovarian cancer using a meta-analysis with 888 subjects. The HER2 gene belongs to the family of tyrosine kinase type I receptors, which was reported to be strongly involved in female cancers. ${ }^{33}$ Importantly, both preclinical and clinical studies indicated that HER2 overexpression is involved in oncogenic transformation and tumorigenesis, accounting for $20 \%-30 \%$ of breast and ovarian cancers. ${ }^{34}$ The mechanism related to the association between the HER 2 gene and ovarian cancer is complex and is still inadequately understood. The homo- or heterozygous Val genotype is associated with an increased risk of breast cancer, ${ }^{35}$ while the results were inconsistent in ovarian cancer. This may be due to the heterogeneity of disease in breast and ovarian cancers. Although a negative result was reported by combined analysis, we could not draw out the genetic association between HER2 rs1801200 (V655I) and ovarian cancer risk. This suggests that more research with larger sample sizes is needed in the future.

Limitations in this study should be mentioned. First, the number of patients was relatively small and may influence the outcome. Only a total of four studies with 348 cases and 540 controls were included for the association between HER2 rs1801200 (V655I) and ovarian cancer in the present meta-analysis. Second, there were only two populations in the subgroup analysis for the HER2 gene and only one

Table 3 Begg's test and Egger's test for funnel plot asymmetries of rs I80 I 200 (V655I), rs I 27 I 572 and rs3020450

\begin{tabular}{|c|c|c|c|c|c|c|c|c|c|c|c|c|}
\hline \multirow{2}{*}{$\begin{array}{l}\text { Models } \\
\text { of test }\end{array}$} & \multicolumn{4}{|c|}{ rsI80I200 (V655I) } & \multicolumn{4}{|c|}{ rs I $27 \mid 572$} & \multicolumn{4}{|c|}{ rs3020450 } \\
\hline & $\mathbf{v}$ & $\mathbf{V v}$ & $\mathbf{V} \mathbf{V}+\mathbf{V} \mathbf{I}$ & VV/II & $\mathbf{T}$ & TT & $\mathbf{T T}+\mathbf{T G}$ & TT/GG & $\mathbf{A}$ & AA & $\mathbf{A A}+\mathbf{A G}$ & AA/GG \\
\hline $\begin{array}{l}\text { Begg's } \\
\text { test }\end{array}$ & 0.734 & 1.000 & 1.000 & 1.000 & 0.711 & 0.063 & 0.108 & 0.062 & 0.296 & 0.296 & 0.296 & 0.117 \\
\hline Egger'test & 0.934 & 0.589 & 0.706 & $0.56 \mathrm{I}$ & 0.305 & 0.099 & 0.065 & 0.031 & 0.050 & 0.150 & 0.059 & 0.184 \\
\hline $95 \% \mathrm{Cl}$ & $\begin{array}{l}-41.4157, \\
43.2700\end{array}$ & $\begin{array}{l}-14.1688 \\
10.510 \mid\end{array}$ & $\begin{array}{l}-20.3479 \\
16.6089\end{array}$ & $\begin{array}{l}-14.6508 \\
10.5964\end{array}$ & $\begin{array}{l}-3.15666 \\
8.49750\end{array}$ & $\begin{array}{l}-0.384899 \\
3.43546\end{array}$ & $\begin{array}{l}-0.075108 \\
1.82562\end{array}$ & $\begin{array}{l}0.201067 \\
2.16302\end{array}$ & $\begin{array}{l}0.023507 \\
10.5435\end{array}$ & $\begin{array}{l}-7.43968 \\
14.7046\end{array}$ & $\begin{array}{l}2.70019 \\
9.89699\end{array}$ & $\begin{array}{l}-10.184 \\
17.53889\end{array}$ \\
\hline
\end{tabular}

Abbreviations: $\mathrm{V}$, val; I, ile; $\mathrm{Cl}$, confidence interval. 
population in the subgroup analysis for SNPs of the ESR2 gene. Third, all the patients in the present study were either Asian or Caucasian, which may limit the general application of the results to other populations. Since genetic variations might be different among different ethnicities, future studies on various ethnicities are needed. Fourth, multiple factors such as reproductive factors, food intake, smoking status and physical activity were reported to contribute to the risk of ovarian cancer. The gene-environmental interaction or gene-gene interaction may also play a role in ovarian cancer risk.

\section{Conclusion}

We found that the allelic and recessive models of ESR2 rs1271572 and the dominant model of ESR2 rs3020450 might be susceptible factors in ovarian cancer.

\section{Acknowledgment}

This study was funded by the Key Foundation of the Education Department of Hunan (16A027), the Foundation of the Education Department of Hunan (15C0513 and 16C0162) and the Foundation of the Health Department of Hunan (B2016096).

\section{Disclosure}

The authors report no conflicts of interest in this work.

\section{References}

1. Bartel F, Jung J, Bohnke A, et al. Both germ line and somatic genetics of the p53 pathway affect ovarian cancer incidence and survival. Clin Cancer Res. 2008;14(1):89-96.

2. Pharoah PD, Ponder BA. The genetics of ovarian cancer. Best Pract Res Clin Obstet Gynaecol. 2002;16(4):449-468.

3. Shen J, Dicioccio R, Odunsi K, Lele SB, Zhao H. Novel genetic variants in miR-191 gene and familial ovarian cancer. BMC Cancer. 2010; 10:47.

4. Easton DF, Bishop DT, Ford D, Crockfor GF. Genetic linkage analysis in familial breast and ovarian cancer: results from 214 families. Am J Hum Genet. 1993;52(4):678-701.

5. Song H, Ramus SJ, Kjaer SK, et al. Tagging single nucleotide polymorphisms in the BRIP1 gene and susceptibility to breast and ovarian cancer. PLoS One. 2007;2(3): 268.

6. Levitus M, Waisfisz Q, Godthelp BC, et al. The DNA helicase BRIP1 is defective in Fanconi anemia complementation group J. Nat Genet. 2005;37(9):934-935.

7. Song H, Ramus SJ, Shadforth D, et al. Common variants in RB1 gene and risk of invasive ovarian cancer. Cancer Res. 2006;66(20): 10220-10226.

8. Doherty JA, Rossing MA, Cushing-Haugen KL, et al. ESR1/SYNE1 polymorphism and invasive epithelial ovarian cancer risk: an Ovarian Cancer Association Consortium study. Cancer Epidemiol Biomarkers Prev. 2010;19(1):245-250.

9. Lurie G, Wilkens LR, Thompson PJ, et al. Estrogen receptor beta rs 1271572 polymorphism and invasive ovarian carcinoma risk: pooled analysis within the Ovarian Cancer Association Consortium. PLoS One. 2011;6(6):9325.
10. Lurie G, Wilkens LR, Thompson PJ, et al. Vitamin D receptor rs 2228570 polymorphism and invasive ovarian carcinoma risk: pooled analysis in five studies within the Ovarian Cancer Association Consortium. Int J Cancer. 2011;128(4):936-943.

11. Zhou H, Luo MP, Schonthal AH, et al. Effect of reproductive hormones on ovarian epithelial tumors: I. Effect on cell cycle activity. Cancer Biol Ther. 2002;1(3):300-306.

12. Treeck O, Pfeiler G, Mitter D, Lattrich C, Piendl G, Ortmann O. Estrogen receptor h1 exerts antitumoral effects on SK-OV-3 ovarian cancer cells. J Endocrinol. 2007;193:421-433.

13. Lindgren PR, Cajander S, Bäckström T, Gustafsson JA, Mäkelä S, Olofsson JI. Estrogen and progesterone receptors in ovarian epithelial tumors. Mol Cell Endocrinol. 2004;221(1-2):97-104.

14. Li AJ, Baldwin RL, Karlan BY. Estrogen and progesterone receptor subtype expression in normal and malignant ovarian epithelial cell cultures. Am J Obstet Gynecol. 2003;189(1):22-27.

15. Xie D, Shu XO, Deng Z, et al. Population-based, case-control study of HER2 genetic polymorphism and breast cancer risk. J Natl Cancer Inst. 2002;94(20):1657-1659.

16. Tripathy D. HER2 status and breast cancer therapy: recent advances. F1000 Med Rep. 2009;1:20.

17. Saxena R, Dwivedi A. ErbB family receptor inhibitors as therapeutic agents in breast cancer: current status and future clinical perspective. Med Res Rev. 2012;32(1):166-215.

18. Revillion F, Bonneterre J, Peyrat JP. ERBB2 oncogene in human breast cancer and its clinical significance. Eur J Cancer. 1998;34(6): 791-808.

19. Pinto D, Vasconcelos A, Costa S, Pereira D, Rodrigues H. HER2 polymorphism and the risk of breast and ovarian cancer. Eur J Cancer Suppl. 2004;2(3):103-103.

20. Mojtahedi Z, Erfani N, Malekzadeh M, Haghshenas MR, Ghaderi A, Samsami Dehaghani A. HER2 Ile655Val single nucleotide polymorphism in patients with ovarian cancer. Iran Red Crescent Med J. 2013; 15(1):1-3.

21. Puputti M, Sihto H, Isola J, Butzow R, Joensuu H, Nupponen NN Allelic imbalance of HER2, variant in sporadic breast and ovarian cancer. Cancer Genet Cytogenet. 2006;167(1):32-38.

22. Watrowski R, Dan CT, Schuster E, Fischer MB, Speiser P, Zeillinger R. Association of HER2 codon 655 polymorphism with ovarian cancer. Tumour Biol. 2016;37(6):7239-7244.

23. Shanmughapriya S, Senthilkumar G, Arun S, Vinodhini K, Sudhakar S, Natarajaseenivasan K. Polymorphism and overexpression of HER2/ neu, among ovarian carcinoma women from Tiruchirapalli, Tamil Nadu, India. Arch Gynecol Obstet. 2013;288(6):1385-1390.

24. Lurie G, Wilkens LR, Thompson PJ, et al. Genetic polymorphisms in the estrogen receptor beta (ESR2) gene and the risk of epithelial ovarian carcinoma. Cancer Causes Control. 2009;20(1):47-55.

25. Schüler S, Lattrich C, Skrzypczak M, Fehm T, Ortmann O, Treeck O. Polymorphisms in the promoter region of ESR2 gene and susceptibility to ovarian cancer. Gene. 2014;546(2):283-287.

26. Leigh PC, Near AM, Butler JL, et al. Comprehensive evaluation of ESR2 variation and ovarian cancer risk. Cancer Epidemiol Biomarkers Prev. 2008;17(2):393-396.

27. Boccia S. PRISMA: an attempt to improve standards for reporting systematic review and meta-analysis. Epidemiol Biostat Public Health. 2009;6(4):352-353.

28. Han Y, Xia Z, Guo S, Yu X, Li Z. Laparoscopically assisted anorectal pull-through versus posterior sagittal anorectoplasty for high and intermediate anorectal malformations: a systematic review and metaanalysis. PLoS One. 2017;12(1):e0170421.

29. Forsti A, Zhao C, Israelsson E, Dahlman-Wright K, Gustafsson JA, Hemminki K. Polymorphisms in the estrogen receptor beta gene and risk of breast cancer: no association. Breast Cancer Res Treat. 2003; 79(3):409-413.

30. Thellenberg-Karlsson C, Lindstrom S, Malmer B, et al. Estrogen receptor beta polymorphism is associated with prostate cancer risk. Clin Cancer Res. 2006;12(6):1936-1941. 
31. Li LC, Yeh CC, Nojima D, Dahiya R. Cloning and characterization of human estrogen receptor beta promoter. Biochem Biophys Res Commun. 2000;275(2):682-689.

32. Haring J, Schuler S, Lattrich C, Ortmann O, Treeck O. Role of estrogen receptor beta in gynecological cancer. Gynecol Oncol. 2012;127(3): 673-676.

33. Graus-Porta D, Beerli RR, Daly JM, Hynes NE. ErbB-2, the preferred heterodimerization partner of all ErbB receptors, is a mediator of lateral signalling. EMBO J. 1997;16(7):1647-1655.
34. Di Fiore PP, Pierce JH, Kraus MH, Segatto O, King CR, Aaronson SA. ErbB-2 is a potent oncogene when overexpressed in NIH/3T3 cells. Science. 1987;237(4811):178-182.

35. Dahabreh IJ, Murray S. Lack of replication for the association between I655V polymorphism and breast cancer risk: a systematic review and meta-analysis. Cancer Epidemiol. 2011;35(6):503-509.

\section{Publish your work in this journal}

OncoTargets and Therapy is an international, peer-reviewed, open access journal focusing on the pathological basis of all cancers, potential targets for therapy and treatment protocols employed to improve the management of cancer patients. The journal also focuses on the impact of management programs and new therapeutic agents and protocols on

\section{Dovepress}

patient perspectives such as quality of life, adherence and satisfaction. The manuscript management system is completely online and includes a very quick and fair peer-review system, which is all easy to use. Visit http://www.dovepress.com/testimonials.php to read real quotes from published authors. 